\title{
Erratum to: Improving the resistance of eggplant (Solanum melongena) to Verticillium wilt using wild species Solanum linnaeanum
}

Jun Liu - Zisong Zheng • Xiaohui Zhou •

Cui Feng $\cdot$ Yong Zhuang

Published online: 28 September 2015

(C) Springer Science+Business Media Dordrecht 2015

Erratum to: Euphytica (2015) 201:463-469 DOI 10.1007/s10681-014-1234-x

Due to an unfortunate turn of events, an incorrect version of Fig. 1 was published causing three panels to be duplicated. The correct images and their caption are published here and should be treated as definitive by the reader.

The online version of the original article can be found under doi:10.1007/s10681-014-1234-x.

J. Liu $\cdot$ Z. Zheng $\cdot$ X. Zhou · C. Feng $\cdot$ Y. Zhuang $(\varangle)$ Institute of Vegetable Crops, Jiangsu Academy of Agricultural Sciences, Jiangsu Key Laboratory for Horticultural Crop Genetic Improvement, 50 Zhongling Street, Nanjing 210014, Jiangsu, China

e-mail: jaaszy@163.com 

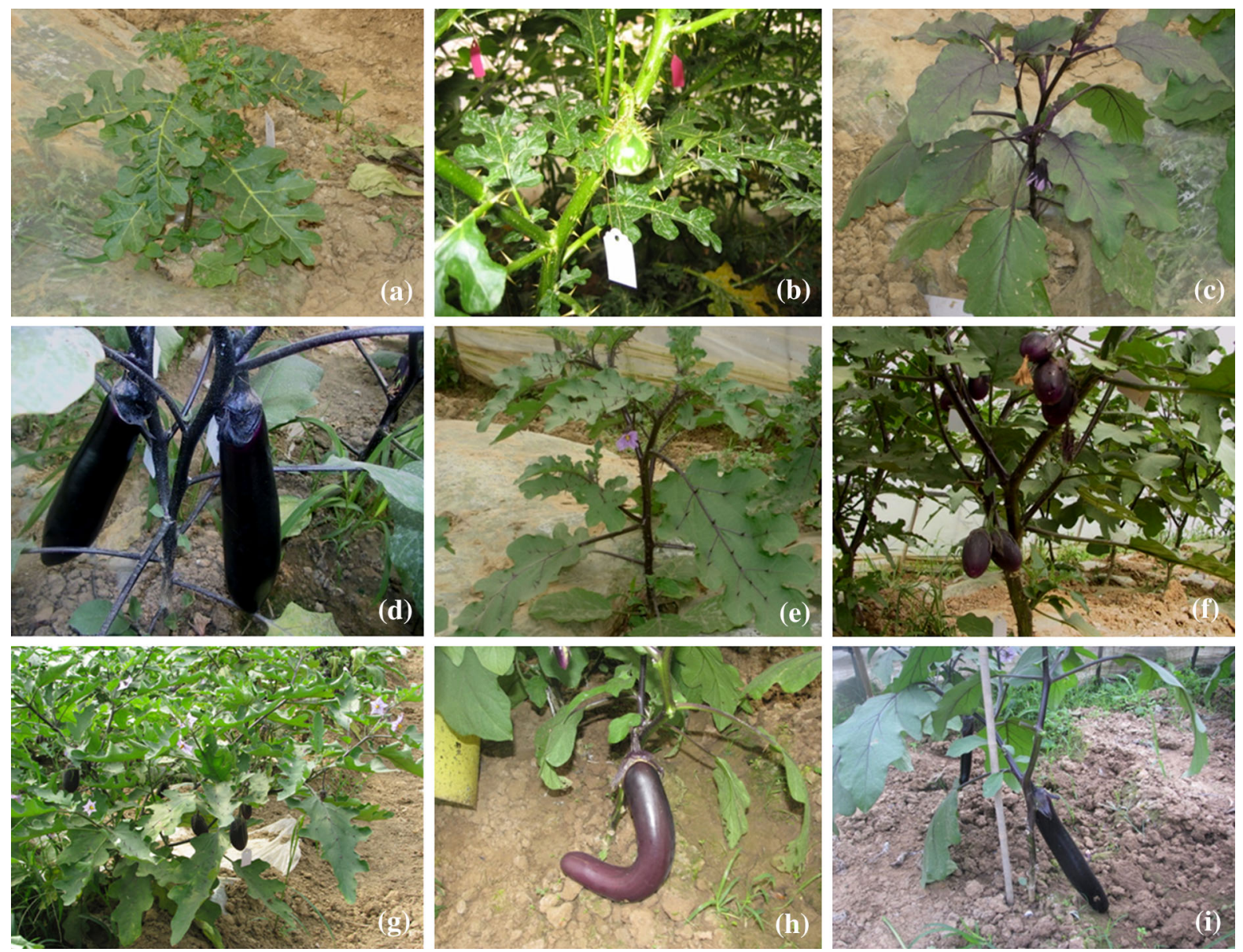

Fig. 1 Agronomic traits of PI388846 (a, b), EP15 (c, d), F1 (e, f) and the representative plants in $\mathrm{BC}_{2}(\mathbf{g}), \mathrm{BC}_{3}(\mathbf{h})$, and $\mathrm{BC}_{4}$ (i) generations 